\title{
The search for compounds that stimulate thermogenesis in obesity management: from pharmaceuticals to functional food ingredients
}

\author{
A. G. Dulloo
}

Department of Medicine/Physiology, University of Fribourg, Fribourg, Switzerland

Address for correspondence: AG Dulloo, Department of Medicine/Physiology, University of Fribourg, Chemin du musée 5, $\mathrm{CH}-1700$ Fribourg, Switzerland. E-mail: abdul.dulloo@unifr.ch

\begin{abstract}
Summary
The concept of managing obesity through the stimulation of thermogenesis is currently a focus of considerable attention by the pharmaceutical, nutraceutical and functional food industries. This paper first reviews the landmark discoveries that have fuelled the search for thermogenic anti-obesity products that range from single-target drugs to multi-target functional foods. It subsequently analyses the thermogenic and fat-oxidizing potentials of a wide array of bioactive food ingredients which are categorized under methylxanthines, polyphenols, capsaicinoids/capsinoids, minerals, proteins/amino acids, carbohydrates/sugars and fats/fatty acids. The main outcome of this analysis is that the compounds or combination of compounds with thermogenic and fat-oxidizing potentials are those that possess both sympathomimetic stimulatory activity and acetyl-coA carboxylase inhibitory property, and are capable of targeting both skeletal muscle and brown adipose tissue. The thermogenic potentials of products so far tested in humans range from marginal to modest, i.e. $2-5 \%$ above daily energy expenditure. With an increasing number of bioactive food ingredients awaiting screening in humans, there is hope that this thermogenic potential could be safely increased to $10-15 \%$ above daily energy expenditure - which would have clinically significant impact on weight management, particularly in the prevention of obesity and in improving the long-term prognosis of post-slimming weight maintenance.
\end{abstract}

Keywords: Bioactive food ingredients, functional foods, obesity, thermogenesis.

\section{Introduction}

In this era when information technology is revolutionizing health awareness among the general public, more and more people are increasingly conscious of the health hazards of excess body fat. This change in perception of excess adiposity from a 'cosmetic' to a 'health' issue is encouraging as it is now acknowledged by the medical establishment that even a modest degree of obesity, particularly if the excess fat is located in the abdomen (1), increases the risks for chronic diseases traditionally associated with more severe obesity, namely type 2 diabetes, cardiovascular diseases and some forms of cancer. However, the cornerstone methods for managing body weight - by dietary restriction and/or by exercise - have proven to be largely ineffective as few people can stick to the hardships of dietary regimens 
for a long time, and compliance to regular exercise is equally poor. The result is generally a transient phase of weight loss (or weight stability) followed by a return on the trajectory towards obesity. These failures to prevent and treat obesity have led to a re-examination of classical views about the causes of this disorder, and indeed a reconsideration of the general concepts of homeostatic mechanisms that regulate body weight and body composition. Although the increasing prevalence of obesity is associated with an environment that encourages over-eating and discourages physical activity, it is now recognized that genetic susceptibilities for a 'slow metabolism' - characterized by a low resting energy expenditure (EE), a low capacity to burn surplus food via diet-induced thermogenesis and/or a low capacity for fat oxidation - also play an important role in determining the extent to which an individual resists or is prone to obesity (2-5). Furthermore, it has long been known that in response to reduced food intake and weight loss (induced by dieting or with the help of anorectic agents), there is an accompanying reduction in EE which is in part due to loss of lean body mass, and in part due to an enhanced metabolic efficiency (6-8). Such reductions in thermogenesis may also persist well beyond the phase of weight loss $(9,10)$, and have been demonstrated in both the resting and non-resting compartments of daily EE (10). These energy-sparing mechanisms not only are counterproductive to the efficacy of the dietary regime in achieving the target weight, but also contribute importantly to weight regain and obesity relapse. Approaches that could dampen these compensatory mechanisms and counteract metabolic predispositions to fatness during weight gain or weight regain are therefore appealing adjuvants to assist the management of obesity. It is towards these conditions of 'slow metabolism' - characterized as diminished thermogenesis and fat oxidation - that considerable research vis-a-vis obesity therapy is directed: that is to say, there is an active search for means of increasing thermogenesis and fat oxidation in weight management.

\section{The search for thermogenic compounds: from a historical perspective}

\section{From thyroid extracts to sympathomimetics}

The idea of stimulating thermogenesis to manage or to assist in the management of obesity has a long history. Thyroid extracts were utilized in obesity therapy at the end of the 19th century, and a few decades later, thousands of obese patients were treated with thyroid hormones and uncoupling agents like dinitrophenol (11). Although they induced marked reductions in body weight, their use in obesity therapy fell into disrepute because of unacceptable side effects, including cardiac stimulation and increased protein catabolism. Numerous other compounds, which can be categorized under hormones (e.g. glucagon, growth hormone), synthetics (e.g. dinitrophenol derivatives, vasodilators such as nicotinic acid, salicylates) or foods (e.g. certain amino acids like glycine, citrus extract, liebig extract), were subsequently tested for thermogenic properties, but their effects on metabolic rate were found to be either insignificant or of too short duration (12). Other compounds like caffeine, theophylline and ephedrine, whose use as bronchodilators in the treatment of asthma peaked in the 1950s, were also long known to have sympathomimetic properties with significant stimulatory effects on resting $\mathrm{EE}(13,14)$. Interests in these drugs capable of mimicking or enhancing the calorigenic effects of catecholamines for weight control only surged in the early 1980s when the pivotal role of the sympatho-adrenal system in the defence of le milieu interieur was extended to the body's fat stores. This followed several lines of evidence suggesting an important role for the sympathetic nervous system (SNS) (via its heat-producing neurotransmitter noradrenaline, NA) in dietary regulation of thermogenesis, and that low SNS activity may contribute to the diminished EE that underlies susceptibility to fatness $(15,16)$. Specifically in the context of dietary management of obesity, the suppression of SNS activity by caloric restriction appears to play an important role in the accompanying adaptive reduction in thermogenesis (15). Hence, compounds that mimic the activity of the SNS and increase thermogenesis therefore offer therapeutic potential, and provide a rational approach in obesity treatment. Additional motivations in the search for sympathomimetic compounds gained momentum in the late 1980s following evidence in support of the notion that fat balance, unlike carbohydrate and protein balances, is not precisely regulated, and that the failure to adjust fat oxidation in response to excess fat intake will result in decreased satiety and increased energy intake (17). Consequently, sympathomimetics have been viewed as agents that - via their stimulatory effects on both thermogenesis and fatty acid oxidation - are capable of exerting their anti-obesity effects by increasing EE and fat oxidation while decreasing appetite.

\section{From classical sympathomimetics to atypical adrenoceptor agonists}

By the early 1990s, virtually all sympathomimetic drugs then in clinical use for a variety of other treatments had been screened for thermogenic anti-obesity properties (18), and the thermogenic properties of clinically relevant doses of caffeine or ephedrine were established not only in lean but also in obese and post-obese humans (19-23). Furthermore, the demonstrations that sympathomimetic stimulation of thermogenesis induced by ephedrine could be potentiated by low doses of methylxanthines (theophylline and/or caffeine) $(24,25)$ or by salicylates like aspirin 


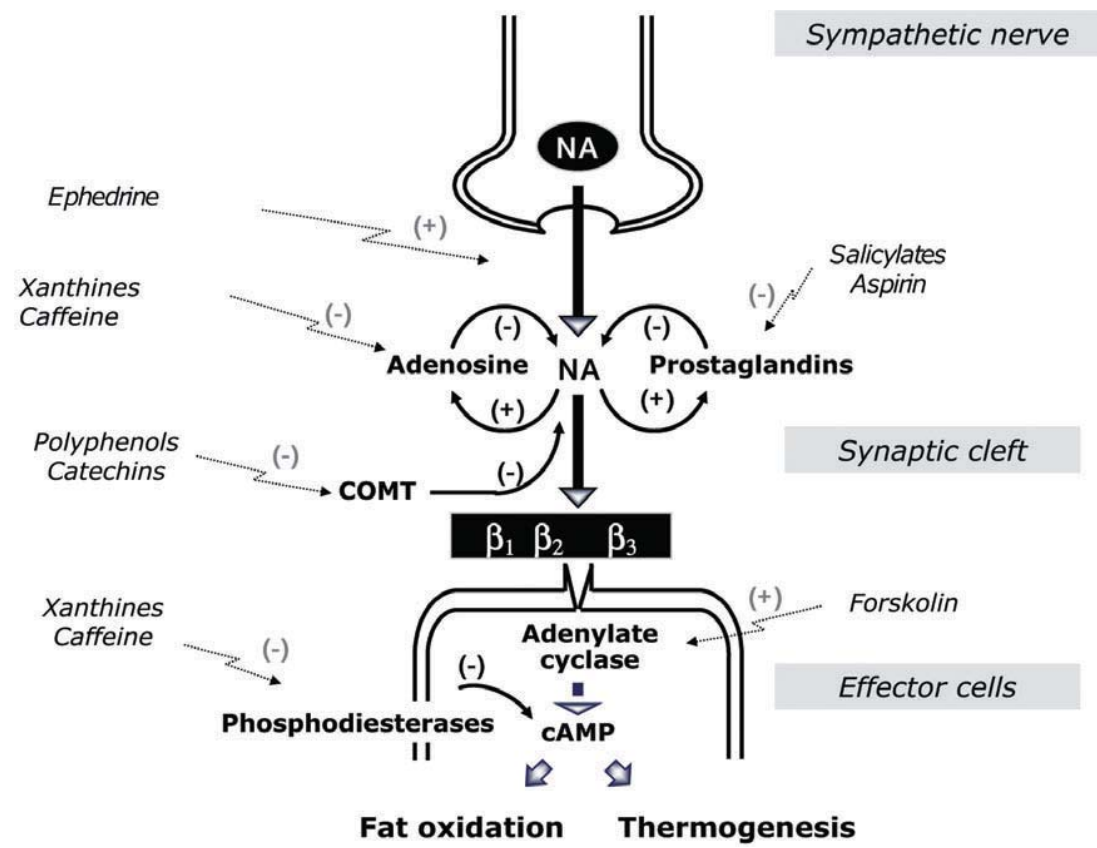

Figure 1 Sympathetically mediated noradrenaline (NA) release and actions (via $\beta$-adrenoceptors) are under negative-feedback modulation by (i) adenosine, certain prostaglandins and catechol-O-methyl transferase (COMT) in synaptic neuroeffector junction and (ii) at cellular level, by phosphodiesterases which break down NA-induced cyclic AMP. Thus, when NA release is enhanced by food ingestion or pharmacologically (e.g. by ephedrine), the inhibitory effects of adenosine, COMT and phosphodiesterases on further NA release and actions could be opposed by xanthines (e.g. caffeine), salicylates (e.g. aspirin) or flavonoid polyphenols (e.g. green tea catechins). Thus, the stimulatory effect of NA on thermogenesis and fat oxidation could be increased and/or prolonged. Adapted from Dulloo (28).
$(26,27)$ - via mode of interactions $(28)$ depicted in Fig. 1 led to the conduct of several controlled clinical trials which showed that various combinations of these drugs had modest anti-obesity efficacy and were well tolerated with side effects considered mild and mostly transient (29-32). There was, however, little or no enthusiasm by the pharmaceutical industry to promote the sale of such sympathomimetic drug cocktails as thermogenic anti-obesity drugs for reasons that included (i) issues of patentability for putting these 'old' drugs (often available over-the-counter) to a new purpose; (ii) risks for hypertension, tachycardia and tremor associated with drugs that could be acting on classical $\left(\alpha_{1}, \beta_{1}\right.$ and $\left.\beta_{2}\right)$ adrenoceptors among a broad spectrum of the population, many of whom may have unrecognized risk factors and (iii) the belief that more selective, safer and more efficacious novel sympathomimetics in development by some pharmaceutical companies would soon become available. It was indeed one of these novel adrenergic agonists that led to the demonstration of atypical adrenoceptors that were eventually cloned and referred to as $\beta_{3}$-adrenoceptors (33). The pharmaceutical approach has since concentrated on the development of drugs that would target specifically atypical $\beta_{3^{-}}$ adrenoceptor, believed to be the pivotal receptor via which sympathetically released NA activates thermogenesis and fat oxidation in peripheral tissues (Fig. 2), including the activation of uncoupling protein (UCP1) that mediates thermogenesis in brown adipose tissue (BAT). In rodents and dogs, several $\beta_{3}$-adrenoceptor agonists were shown to have potent thermogenic anti-obesity effects - without producing the cardiovascular side effects associated with classical adrenoceptor stimulation (34). However, despite the

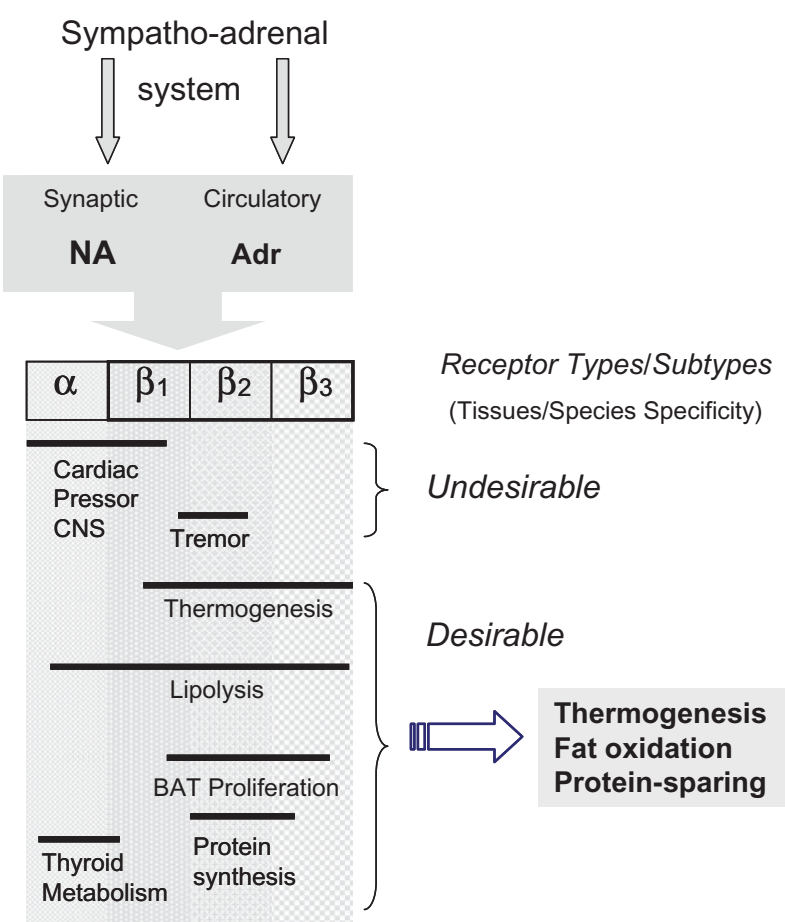

Figure 2 Concepts in targeting the peripheral adrenergic system in anti-obesity therapy (adapted from Dulloo (28)). See text for details. Adr, adrenaline; BAT, brown adipose tissue; CNS, central nervous system; NA, noradrenaline.

demonstration that $\beta_{3}$-adrenoceptors are also present in human adipose tissue and skeletal muscle, the translational research from rodents to humans proved disappointing. Whereas the first-generation compounds had poor selectiv- 
ity as agonists of the human cloned $\beta_{3}$-adrenoceptor, the second-generation compounds, which showed greater selectivity for human $\beta_{3}$-adrenoceptors, had poor oral bioavailability or were rapidly excreted. Moreover, $\beta_{3}$-adrenoceptor agonists have less effect on EE in humans than in rodents, and although some compounds when administered over a few weeks led to weight loss, this was too modest to be considered sufficiently exciting for longer trials (34). Overall, despite the attempts of many pharmaceutical companies to develop $\beta_{3}$-adrenoceptor agonists for the treatment of obesity, there is no report of a compound that has progressed beyond phase II clinical trials (34).

\section{From $\beta_{3}$-adrenoceptor agonists to acetyl-CoA carboxylase 2 inhibitors}

A turning point in the search for molecular targets to enhance fat oxidation occurred in the early 2000s with the implication of the AMP-activated protein kinase (AMPK) signalling pathway in the stimulation of fatty acid oxidation by the leptin-SNS axis (35). Activation of AMPK is thought to convey many of the beneficial effects of exercise by inhibiting the activity of the enzyme acetylCoA carboxylase 2 (ACC2), thereby facilitating the entry of fatty acyl-CoA into the mitochondria leading to increased fat oxidation. The demonstrations that mice with deletion of the ACC2 gene are resistant to obesity (36) and show increased fatty acid oxidation coupled with elevated whole-body EE (37) provided considerable support to the concept of 'push' routes to increased fat oxidation (38) in that increased flux of fatty acids into mitochondria might be sufficient to trigger increased whole-body EE and leanness. Although the mechanisms by which an enhanced fat oxidation would drive energy dissipation are not understood, AMPK and ACC2 have become major anti-obesity and anti-diabetes drug targets (39). However, a recent re-examination of this relationship between increased fatty acid oxidation and reduced adiposity using both pharmacological and genetic approaches (mutation of the ACC2 gene in mice) does not support the hypothesis that increased fatty acid oxidation per se leads to diminished body fat (40). Although both of these strategies increased whole-body fatty acid oxidation, they failed to increase EE and to reduce adiposity, the previous reports of the opposite being attributed to technical issues and artefacts in mouse genetic manipulation (40). The more recent findings in mice (40) are consistent with other studies in rats showing that a non-selective ACC1/2 inhibitor decreased respiratory quotient over a 3-h period without altering EE (41) and that reduced ACC1/2 expression in rat liver and adipose tissue using antisense oligonucleotides was without effect on body weight (42). Taken together, these data indicating that fat oxidation and thermogenesis are not necessarily coupled cast serious doubts about the belief that fat oxidation per se drives leanness. Rather, the increased fat oxidation may be offset by alterations in the handling of other macronutrients, and hence consistent with the glucose-fatty acid cycle proposed by Randle 50 years ago (43). In this context, the question arises as to whether drug targeting of fat oxidation at the expense of carbohydrate oxidation is desirable as this could lead to impaired glucose uptake by metabolic feedback. This issue of whether it is good or bad to increase fat oxidation (in the absence of an increase in EE) pertaining to substrate competition and insulin sensitivity is discussed in greater depth by Kiens et al. (44) in an accompanying article about potential targets in the regulation of fat metabolism.

\section{From pharmacotherapy to phytotherapy}

The difficulties of the pharmaceutical industry in producing drugs with good efficacy, selectivity and pharmacokinetic properties suitable for stimulation of the small number of $\beta_{3}$-adrenoceptors present in humans, uncertainties about the future of research and development for ACC2 inhibitors, together with the lack of interest in marketing ephedrine, caffeine and/or aspirin combinations for anti-obesity therapy, have created and sustained a vacuum in the market for pharma-grade thermogenic products. This vacuum has long been filled by the commercialization of a plethrora of botanical or herbal products, whose pharmacologically active ingredients would act at one or more control points along the line of SNS control of thermogenesis and fat oxidation (Fig. 1). It is estimated that some 12 million people in the USA utilized these herbal supplements in 1999 alone (45), often as mixtures of Ma Huang (a source of ephedra alkaloids), Guarana or kola nuts (sources of caffeine), bark of willow (source of salicylates), and Coleus Forskohlii whose active ingredient - forskolin - enhances cAMP formation through stimulation of adenylate cyclase. Not surprisingly, their sales under the category of dietary supplements were promoted with the findings of safety and efficacy derived from controlled studies with pharmaceutical grades of these compounds (29-32), and subsequently by a few short-term small-size clinical trials reporting weight loss efficacy and relative safety of herbal preparations of ephedra and guarana or kola nuts $(46,47)$. However, because of the publicity of adverse reactions to ephedra-containing products and the high potential for abuse when such botanical products are available to the general public, many of whom may have unrecognized risk factors, the sales of ephedra has been banned in the USA and other countries (48). As a result, many companies have since altered their botanical preparations by substituting ephedra with Citrus aurantium (bitter orange), whose major bioactive ingredients are 
synephrine alkaloids, which act on both $\alpha^{-}$and $\beta$-adrenoceptors and which have been shown to increase resting EE acutely in humans (49). At present, Citrus aurantium is considered by some to be the best thermogenic substitute for ephedra (50), but the few small-size short-duration studies that have reported greater weight losses with Citrus aurantium products cannot be considered as conclusive regarding the safety and efficacy, and furthermore they do not separate the effects of Citrus aurantium from those of other ingredients in these products (51). Among other herbal products for weight control with claims (52) for their fat oxidation properties is Garcinia cambogia, a natural fruit acid extracted from the rind of the brindall berry which contains (-)-hydroxycitrate - a compound which Sullivan et al. (53) showed in the early 1970 s to potently inhibit the extramitochondrial enzyme citrate lyase, a key enzyme involved in de novo lipogenesis. Thus, by inhibiting the lipogenic machinery, hydroxycitrate has the potential to shift fat metabolism from synthesis/storage towards oxidation. However, the findings from a controlled study that $3 \mathrm{~d}$ of hydroxycitrate $\left(3 \mathrm{~g} \mathrm{~d}^{-1}\right)$ supplementation to a typical Western diet failed to alter the short-term rate of fat oxidation (54) raise doubts about the purported mode of action of hydroxycitrate per se. Furthermore, studies that have provided evidence in support of the efficacy of hydroxycitrate in weight loss are those in which hydroxycitrate was administered together with other ingredients, so that the anti-obesity efficacy of hydroxycitrate per se cannot be evaluated. A randomized double-blind placebo-controlled trial lasting for 3 months found no difference in body weight nor body fat losses in subjects receiving the active herbal compound containing hydroxycitrate $\left(1,500 \mathrm{mg} \mathrm{d}^{-1}\right)$ compared to placebo (55).

\section{From phytotherapy to functional food ingredients}

Although the market for weight-loss products that contain a multitude of sympathomimetics and claimed fatoxidizing ingredients continues to flourish, the past decade has also seen growing interests by mainstream pharmaceutical and food industries towards the development of thermogenic and 'fat-burning' nutraceuticals or functional foods. This has invigorated both basic and applied research into the area of bioactive food ingredients for weight management, leading to investigations into an increasing array of dietary micro-components, but also macro-components, that cut across both plant and animal products for potential stimulatory effects on thermogenesis and fat oxidation. An overview of this rapidly advancing research field is presented below, with the focus on food ingredients derived from fruits, vegetables, herbs, spices, meat and dairy products, and categorized under methylxanthines, polyphenols, capsaicinoids/capsinoids, minerals, proteins/amino acids, carbohydrates/sugars and fats/fatty acids.

\section{Bioactive food ingredients: thermogenic and fat-oxidizing potentials}

\section{Methylxanthines}

The ability of caffeine - the most abundant dietary methylxanthine - to stimulate metabolic rate was demonstrated in humans almost a century ago (13). Studies conducted several decades later, in the 1980s, established that caffeine was also effective in stimulating resting $\mathrm{EE}$ in both the post-absorptive and postprandial states in lean, obese and post-obese subjects (19-21), often associated with increases in circulating free fatty acid and fat oxidation $(19,20)$. Using indirect calorimetry coupled with ${ }^{13} \mathrm{C}$ labelled palmitate measurements to trace lipid oxidation and free fatty acid turnover, Acheson et al. (56) have more recently shown that although caffeine ingestion $\left(10 \mathrm{mg} \mathrm{kg}^{-1}\right)$ in young men increased resting EE by $13 \%$ and caused a doubling in fatty acid turnover, only $24 \%$ were oxidized, indicating that most mobilized fatty acids are recycled through re-esterification. They proposed that as exercise causes an increase in the turnover of fatty acids, of which most $(70-80 \%)$ are oxidized (57), the combined stimulation of lipolysis by caffeine administration and stimulation of EE by exercise may prove more effective in enhancing fat oxidation than giving caffeine alone. An analysis of literature data on the effect of single-dose administration of caffeine on resting EE after an overnight fast suggests a dose-effect relationship with the threshold for a detectable stimulatory effect $(+5 \%)$ occurring between 50 and $100 \mathrm{mg}$ - which corresponds to the amount of caffeine in a cup of coffee or tea. Repeated administration of such low doses of caffeine $(100 \mathrm{mg})$ at regular 2-h intervals between 8:00 h and 18:00 h (i.e. total of $600 \mathrm{mg} \mathrm{d}^{-1}$ ), during time spent in a whole-body respiratory chamber, was found to increase 24-h EE by $5 \%$ in both lean and post-obese individuals (21). Similarly, repeated intake of caffeinated coffee, containing higher doses of caffeine $(250 \mathrm{mg}$ per cup, five cups per day, i.e. $1,250 \mathrm{mg} \mathrm{d}^{-1}$ ), was also shown to increase $24-\mathrm{h}$ EE by $8 \%$ and $5 \%$ in lean and obese subjects respectively (58), without apparent side effects, no difference in heart rate nor alterations in protein oxidation or non-protein respiratory quotient, suggesting an increase in both fat and carbohydrate oxidation. There was, however, a tendency for respiratory quotient to be lower during sleep, and a significant decrease in respiratory quotient relative to placebo was observed the following morning, suggestive of a selective increase in post-absorptive fat oxidation (58). Despite these quantitatively important thermogenic effects of caffeine when assessed over $24 \mathrm{~h}$ under weight maintenance conditions $(21,58)$, obese individuals ingesting $200 \mathrm{mg}$ three times a day $\left(600 \mathrm{mg} \mathrm{d}^{-1}\right)$ in conjunction with a hypocaloric diet lost no more weight than those on 
placebo (29). Overall, caffeine certainly possesses substantial thermogenic properties (fuelled partially or almost completely by lipids), which might assist in the prevention of weight gain and weight regain, but these effects would seem to be absent during the dynamic phase of weight loss in response to caloric restriction, possibly because of the accompanying reduction in SNS activity, and hence less negative modulators of NA release and action (e.g. adenosine, phosphodiesterase activity) to inhibit (Fig. 1). This contention is supported by the fact that low doses of methylxanthines (theophylline and/or caffeine) were found to be effective in potentiating the thermogenic effects of the NA-release enhancer ephedrine $(24,25)$, and that a combination of ephedrine and caffeine resulted in greater fat losses than either ephedrine or caffeine alone in women on a hypocaloric diet (29).

\section{Polyphenolic compounds}

Although the role of plant polyphenols in health and diseases has been an active area of research for many decades, interest in the potential role of these phytochemicals in energy metabolism and obesity research is only a decade old. This followed the demonstration (59) that ingestion of capsules of a green tea extract - providing $125 \mathrm{mg}$ catechin polyphenols and $50 \mathrm{mg}$ caffeine with each of three meals over the day, resulted in a $4 \%$ increase in $24-\mathrm{h} \mathrm{EE}$, a shift from carbohydrate to fat oxidation and increased urinary NA excretion - metabolic effects that were not found to be mimicked by ingestion of the same amount of caffeine as found in the green tea extract (59). Given evidence that polyphenols of the class of flavonoids, which includes catechins, are capable of inhibiting catechol-o-methlyl transferase (COMT) (60-62), an enzyme that degrades NA (Fig. 1), the proposal was put forward that by virtue of its content in both catechin polyphenols (which may hence reduce the degradation of NA within the synaptic cleft) and caffeine (which inhibits phosphodiesterase within the cytoplasm), green tea has thus the potential to interact synergistically with the SNS leading to the potentiation and prolongation of NA-induced thermogenesis and fat oxidation (59). Such mechanistic proof-of-concept was subsequently supported by ex vivo microcalorimetry studies (63) in rat BAT, which demonstrated synergistic thermogenic interactions between sympathetic neural release of NA, caffeine and epigallocatechin gallate (EGCG), the most abundant of green tea catechins. Further evidence that caffeine and EGCG interact to enhance 24-h EE in humans may also be obtained from an analysis of data (reported here in Fig. 3) derived from several studies that compared, by regression analysis, the increase in $24-\mathrm{h} \mathrm{EE}$ in response to the intake of different doses of caffeine $(21,58,59,64)$ versus that in response to intake of green or oolong tea products containing both caffeine and catechins, the

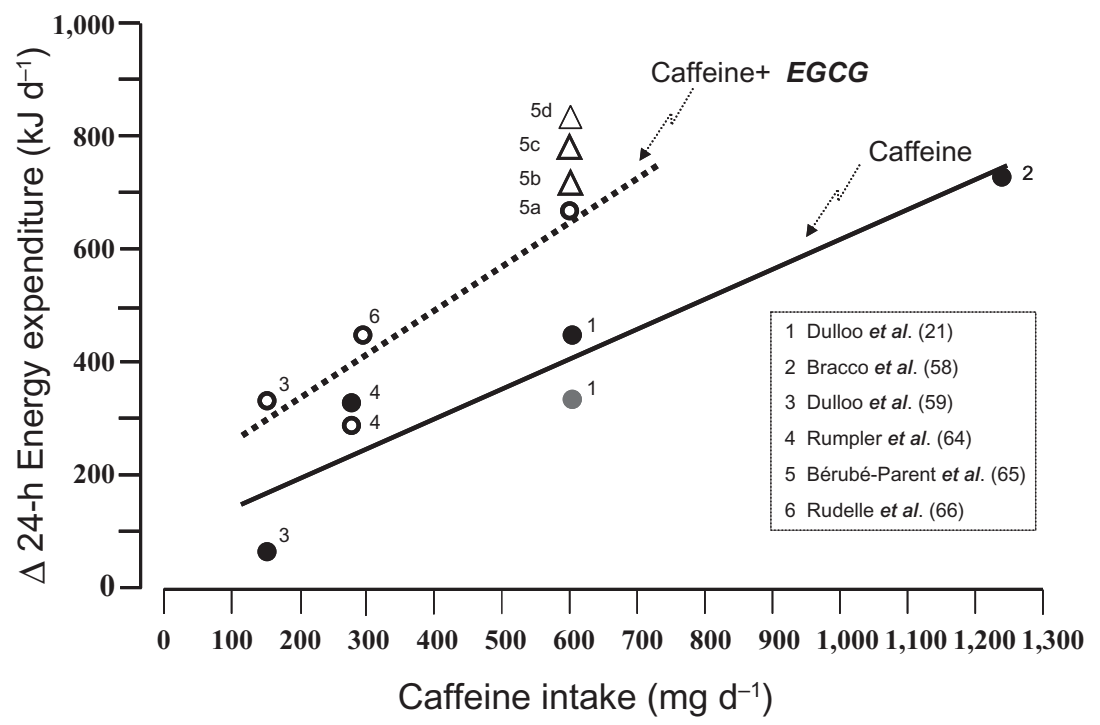

Figure 3 Regression analysis of data on mean changes in 24-h energy expenditure (EE), assessed in respiratory chambers, in non-obese humans in response to either caffeine $(21,58,59,64)$ presented as filled circles or to green or oolong tea products containing both caffeine and catechins $(59,64-66)$ presented as open circles and in which the epigallocatechin gallate (EGCG) intakes are similar across these studies - within the narrow range of 244-282 $\mathrm{mg} \mathrm{d}^{-1}$. The black and grey filled circles for study 1 (21) represent data for never-obese and post-obese subjects, respectively. The open triangles (in study 5) represent additional data (65) in response to green tea products containing much higher amounts of EGCG, namely 600, 900 and 1,200 mg; they are not part of the regression analysis here. Statistical comparisons of the two regression lines for equality of variance, slopes and elevations indicate significant differences $(P<0.05)$ only in their elevations. The data were analysed by the computer software STATISTIK 8 (Analytical Software, St Paul, MN, USA). Note also that within the study 5 (65), there is a graded increase in mean 24-h EE in response to 600-mg caffeine and varying intakes of catechins as EGCG - namely 270, 600, 900 and 1,200 $\mathrm{mg} \mathrm{d}^{-1}$ designated as 5a, 5b, 5c and 5d, respectively. 
intake of EGCG being similar (244-282 $\mathrm{mg} \mathrm{d}^{-1}$ ) across these studies $(59,64-66)$. This regression analysis suggests that for the caffeine intake across the range of 150 $600 \mathrm{mg} \mathrm{d}^{-1}$, the increase in 24-h EE is shown to be greater with products containing both caffeine and EGCG than caffeine alone. Furthermore, the data of Bérubé-Parent et al. (65) suggest a tendency towards a dose-response increase in 24-h EE with increasing EGCG intake in the range of $270-1,200 \mathrm{mg}$ in combination with $600 \mathrm{mg}$ of caffeine. A number of studies have also addressed the question of whether green tea catechins, in their own rights (i.e. in the absence of caffeine), can enhance $\mathrm{EE}$ and fat oxidation. In this context, a caffeine-free green tea extract has been reported to improve fat oxidation during moderateintensity cycling exercise in healthy young men (67), while the ingestion of a commercially available EGCG supplement was found to be effective in enhancing postprandial fat oxidation at rest in overweight/obese men (68), but not in lean men (69). A common denominator in the latter studies is that none of them found an increase in resting EE in response to ingestion of the commercially available EGCG $(68,69)$. Taken together, these results underscore the possibility that in humans, in line with what was demonstrated by microcalorimetry studies in rat BAT (63), the thermogenic effects of green tea reside in the synergistic interactions between catechins, caffeine and sympathetically released NA. These interactions along the NA-cAMP pathway may thus require a modest enhancement in sympathetic tone as would occur after meals and/or during the type of low-level spontaneous activity that humans often exhibit even during confinement in respiratory chambers (70). It should also be noted that studies lasting for $13.5 \mathrm{~h}$ to $24 \mathrm{~h}$ in respiratory chambers show a greater tendency (albeit not always statistically significant) for a reduction in respiratory quotient (i.e. selective increase in fat oxidation) in response to ingestion of green tea products containing both caffeine and catechins than with caffeine alone $(59,64,65,71)-$ a contention which is reinforced by the results of a recent meta-analysis by Hursel et al. (72). These thermogenic effects of green tea fuelled at least in part by an increase in fat oxidation may thus contribute importantly to the reported efficacy of green tea products in inducing an extra 1-2 kg weight loss and/or abdominal fat losses observed in controlled clinical trials lasting from a few weeks to a few months $(73,74)$, and to a better post-slimming weight maintenance through increased thermogenesis and fat oxidation (75). A mechanistic model that integrates animal and human data to explain the antiobesity properties of green tea has recently been proposed by Thavanesan (76).

\section{Other polyphenols}

During the past few years, a wide variety of polyphenolic products and compounds belonging to several classes and subclasses of polyphenols (in particular flavonoids) have also been shown to possess properties that could potentially lead to enhance thermogenesis and fat oxidation, namely:

1. A polyphenol-rich insoluble dietary fibre preparation from carob pulp (rich in gallic acid, gallotannins and flavonol glycosides) has been shown to increase postprandial EE and reduced respiratory quotient in humans (77).

2. Resveratrol and quercetin, two quantitatively important grape polyphenols, may possess such thermogenic properties, as judged by studies showing that resveratrol supplementation to mice fed on a high-fat diet resulted in more hepatic mitochondria and elevated whole-body EE (78), while quercetin supplementation to untrained humans led to increases in skeletal muscle mitochondrial density (79) as well as improved fitness and endurance capacity without prior training (80). There is no report yet about whether these or other grape polyphenols impact upon metabolic rate and substrate oxidation in humans, but this would be an interesting line research in view of the recently reported effects of polyphenol-rich grape extracts in preventing obesity in hamsters (81), and weight gain in overweight men and women (82).

3. Oleuropein, a phenolic compound in extra virgin olive oil, has been shown to enhance catecholamine secretion and to increase UCP1 in BAT of rats (83), while lemon polyphenols (hesperidin) suppress diet-induced obesity associated with the up-regulation of gene markers of lipid oxidation in mouse white adipose tissue (84).

4. Other polyphenols like circumin (rich in the spice turmeric) or chlorogenic acid (rich in coffee beans) when supplemented to mice on a high-fat diet resulted in lower body weight and fat gain than controls, apparently without a decrease in food intake, thereby raising the possibility that the anti-obesity effects of these polyphenols reside primarily in increasing faecal fat losses and/or via the stimulation of EE $(85,86)$.

5. Similarly, dietary supplementation with soy isoflavones has been shown to decrease fat accumulation in several animal models of obesity (87), and mice exposed to dietary phytoestrogens maintain a lean phenotype associated with increased EE coupled with a marked shift towards the use of lipids (88).

6. Finally, the small polyphenolic flavonol molecule kaempferol (found in broccoli, spinach, berries) increases cellular EE and thyroid hormone activation through the stimulation of deiodinase type 2 activity in human skeletal muscle myoblast (89).

Thus, it is highly likely that in the coming years, polyphenolic compounds will be a focus of research for thermogenic anti-obesity effects in humans - a contention reinforced by the results of a recent longitudinal analysis 
from the Netherland cohort study indicating that higher dietary flavonoid intakes in women are associated with lower weight gain over a 14-year period (90).

\section{Capsaicinoids and capsinoids}

Interests in pungent spices as potentially containing thermogenic ingredients were probably triggered by their apparent ability to 'subjectively' warm the body. More objective evidence for spice-induced thermogenesis was first provided by Henry and Emery (91), who showed that chilli and mustard sauces augmented the thermogenic response to a meal. This was followed nearly a decade later by demonstrations of Yoshioka et al. (92) that red pepper also enhanced thermogenesis and fat oxidation in Japanese women. It is now established from animal studies that the principle ingredients that confer pungency to these spices (and to others such as Tabasco sauce and ginger), namely the capsaicinoids (capsaicin and dihydrocapsaicin) and capsaicinoid homologues (the gingerols, shogaols and zingerone), contribute to their thermogenic, lipolytic and fat-oxidizing properties (93). These metabolic effects of pungent principles of spices are perhaps not unexpected in view of evidence in animals suggesting that their main modes of action can also be linked to interference with the sympathoadrenal system, either centrally to induce adrenal medullary secretion or peripherally by interference with SNS control in tissues such as muscle and adipose tissue (93). In humans, power spectral analysis of heart rate has suggested that the anorexigenic and thermogenic effects of red pepper in combination with caffeine could be associated with an increase in sympathetic: parasympathetic nervous system activity ratio (94). It should be pointed out, however, that the red pepper doses provided in the above-mentioned studies (up to $10 \mathrm{~g}$ per meal) are high, and largely exceed the amount preferred by the general population in many countries, such as in the USA and Europe, where the intake is $\sim 1 \mathrm{~g}$ per meal. Given their strong pungency, not all people may feel comfortable consuming several folds their habitual intake. Interestingly, oral or capsular ingestion of hedonically acceptable red pepper doses, in single dose, has also been shown to enhance thermogenesis (and to produce moderate orexigenic sensations) in young adults subgrouped as spicy food users and non-users, with oral exposure being shown to be necessary to achieve red pepper's maximum effects on energy balance (95). Other capsaicin-like compounds such as capsinoids (i.e. capsiate, dihydrocapsiate and nordihydrocapsiate) are much less pungent, but they can also increase the activity of the SNS, thermogenesis and fat oxidation. In human subjects, ingestion of capsinoids-rich peppers $(\mathrm{CH}-19$ sweet; Capsicum annumm) was found to increase body temperature and resting EE (96), while ingestion of $10 \mathrm{mg}$ of capsi- noids was shown to increase plasma NA and EE at rest, and resulted in a shift in substrate utilization towards lipids (97). Furthermore, a significant increase in resting $\mathrm{EE}$ in response to $3-9 \mathrm{mg} \mathrm{d}^{-1}$ of dihydrocapsiate was demonstrated in healthy subjects after daily intake of capsinoid for $28 \mathrm{~d}$ (98). Thus, given the lack of pungency, the use of capsinoids may represent a more viable longer-term adjunct therapy for the management of overweight and obesity as it has been shown to enhance fat oxidation and reduce abdominal fat in overweight individuals (99).

\section{Minerals}

A role for dietary calcium in the regulation of body weight and body composition has been advocated by Zemel (100) on the basis that dietary calcium, via its effects on plasma 1,25-dihydroxyvitamin $\mathrm{D}_{3}$ (calcitriol), regulates adipocyte intracellular concentrations of calcium, which in turn regulates lipid metabolism in the adipocytes. According to this hypothesis, centred on the notion that a low dietary calcium intake inhibits lipolysis, stimulates de novo lipogenesis and inhibits fat oxidation, a low dietary calcium intake would lead to weight gain, whereas a high dietary calcium intake would result in weight loss. This concept was initially supported by studies in mice and human showing that dietary calcium drives the partitioning of energy towards lean body mass rather than adipose tissue, particularly when the diet has a high dairy component (100). Furthermore, dietary calcium supplementation in mice was reported to increase the core temperature, which was interpreted as an increase in thermogenesis and fat oxidation (100). However, in a placebo-controlled, crossover experiment in overweight human subjects who were low-calcium consumers, Bortolotti et al. (101) showed that 5 weeks of dairy calcium supplementation at $800 \mathrm{mg} \mathrm{d}^{-1}$ in these men and women failed to alter adipose tissue lipolysis and lipid oxidation, and furthermore EE under resting conditions and during acute stimulation with caffeine (300 mg) was not altered. Similarly, Boon et al. (102) also reported that calcium supplementation (400$2,500 \mathrm{mg} \mathrm{d}^{-1}$ ) to lean young men for a week had no impact on markers of adipose tissue lipid metabolism nor on resting EE or fat oxidation. These studies therefore do not lend support to the hypothesis that dietary calcium per se plays a role in human energy balance through calciumcontrolled pathways in adipose tissue or through enhanced thermogenesis. More recently, however, a role for calcium in combination with vitamin D in the regulation of energy balance has been proposed by Chan She Ping-Delfos and Soares (103) on the basis that high calcium and vitamin D intake at breakfast acutely increased postprandial thermogenesis and fat oxidation over two successive meals, and reduced spontaneous energy intake in the subsequent 24-h 
period. Furthermore, there are reports that obese women who received mineral tablets containing mainly calcium and potassium phosphates show significant increases in resting EE than subjects receiving placebo tablets (104). Interestingly, the addition of $\mathrm{K}$ - and $\mathrm{Mg}$-phosphates to glucose in orange juice drinks has been shown to increase resting EE by about $15 \%$ in obese women $(105,106)$. The role of minerals and vitamins on EE and substrate oxidation deserves further evaluation.

\section{Protein types and amino acids}

It has long been established that, of the three macronutrients, protein has the highest satiating power and greatest thermic effect compared to isocaloric amounts of carbohydrates or fat - properties that underscore the appeal for high-protein diets in weight management. There are, however, concerns that high-protein diets may have longterm detrimental effects, particularly on renal functions (107). Consequently, altering the type or source of protein rather than the amount of protein might represent a safer and more effective approach for obesity management. This issue is of particular interest in the light of evidence indicating that certain protein types or specific amino acids supplementation may favour fat oxidation - often associated with increased BAT growth and/or BAT-UCP1 up-regulation, and hence suggestive of increased SNS activity - or a shift in nutrient partitioning towards lean tissue at the expense of fat deposition. Lower adiposity and improved insulin sensitivity have been reported in animals fed on diets rich in soy protein (108), fish protein $(109,110)$ or whey protein $(111,112)$ when compared to casein-based diets, as well as in animals fed on diets supplemented with glycine (113) or glutamine (114). Supplementation with leucine (115) or arginine (116) has also been reported to increase nutrient partitioning to lean body mass at the expense of fat mass accretion, often accompanied with improved insulin sensitivity. Furthermore, there is also evidence from longitudinal studies in children $(117,118)$ that higher consumptions of arginine and lysine are associated with greater gain in lean body mass and lower gain in fat mass, effects on body composition that have been attributed to the ability of arginine and lysine to increase growth hormone secretion and/or action. To what extent these protein types and specific amino acid supplementation also influence thermogenesis and fat oxidation is not clear. In humans, only a few studies have examined the role of protein sources on EE and substrate oxidation. A study by Mikkelsen et al. (119) reported a marginally higher $24-\mathrm{h}$ EE $(+2 \%)$ in subjects when consuming a pork-meat protein diet than when on a soy-protein diet for $4 \mathrm{~d}$, but two recent studies comparing the thermic effects of isocaloric high-protein meals based upon casein, whey and soy, reported contradictory results.
Whereas whey protein was shown by Acheson et al. (120) to elicit a greater thermic response (and tendency for higher fat oxidation) than does protein composed of either casein or soy, Alfenas Rde et al. (121) found greater fat oxidation after a breakfast meal containing whey protein than after meals containing casein or soy protein, but a higher thermic effect with soy protein than with casein or whey. Longer-terms studies are warranted in elucidating whether protein sources and amino acid supplementation influence EE and substrate metabolism, while keeping in mind that excess amino acids and their products can result in adverse effects (including neurological disorders, oxidative stress and cardiovascular diseases) owing to amino acid imbalance or antagonism (122).

\section{Carbohydrate types and simple sugars}

Differences in postprandial thermogenesis in response to ingestion of monosaccharides, disaccharides and mixtures of monosaccharides were first documented in humans by Macdonald and colleagues $(123,124)$, who showed that the greater thermic effect of sucrose compared to other disaccharides (maltose and lactose) could be attributed to its fructose moiety. A greater thermic effect of ingested fructose than glucose or starch has since been well established in both lean and obese subjects $(125,126)$, and is to a large extent explained by the high ATP requirements linked to fructose-induced gluconeogenesis, with possible contribution of de novo lipogenesis (125). Although fructose was initially thought to be advisable for patients with diabetes because of its low glycaemic index, there is now compelling evidence in animals, and increasing evidence in humans, that chronically high consumption of fructose (as sucrose or as high-fructose corn syrup) can lead to adverse lipid profile and increased diabetes and cardiovascular risks (127). This contention is underscored by the recent demonstration that although sustained consumption of glucoseor fructose-sweetened beverages for 10 weeks led to similar weight gain in overweight and obese adults, dietary fructose specifically increased visceral adiposity and dyslipidaemia, and decreased insulin sensitivity (128). Furthermore, chronic energy balance studies comparing diets enriched with sucrose/fructose or glucose/starch in laboratory rats and mice have failed to detect differences between these sugar-enriched diets on whole-body EE and on the efficiency of fat deposition during weight gain (129) or weight regain (130). These data on energy balance are consistent with the reported lack of differences in SNS recruitment of BAT in rats in response to diets in which the various types of dietary carbohydrates (fructose, sucrose, dextrose or corn starch) contributed $50 \%$ of energy intake (131). In the coming years, it is likely that more attention will be directed at the chronic effects of milk sugars (lactose and its constituent galactose) on energy metabolism. This 
follows the demonstrations in rats that, unlike glucose or fructose, diets enriched in galactose led to reduced weight gain associated with markedly increased SNS activity in epididymal fat pads (132), and that the addition of lactose to a high-fat diet fed to rats for 12 weeks led to decreased efficiency of fat accumulation (133). Furthermore, the recent findings in obese women that oral consumption of galactose-enriched beverages promotes postprandial fat mobilization and fat oxidation without adversely affecting milk production in those who were lactating (134) may have implications for dietary strategies in the management of obesity after pregnancy. Finally, in addressing the topic of carbohydrate types and thermogenesis, it is conceivable that the physical properties of certain dietary fibres or non-starch polysaccharides (NSP) can influence EE by, for example, increasing the mass and turnover of tissues of the gastrointestinal tract or via changes in microbiota and the gut-brain axis controlling thermogenesis. To date, however, studies conducted over 1-3 weeks in humans whose diets were either supplemented with NSP (135), or intrinsically high in NSP relative to a usual mixed diet (136), have failed to show that increased ingestion of NSP led to increased 24-h EE beyond the theoretical increase in heat production due to carbohydrate fermentation. Whether dietary supplementation with certain specific types of fibres may confer thermogenic properties that could be advantageous for body weight control thus remain to be demonstrated.

\section{Fat types and fatty acids}

Fat in the typical Western diet consists essentially of saturated and unsaturated long-chain triglycerides (LCT), which are derived from animal fat and vegetable oils. In some countries, medium-chain triglycerides (MCT), derived from coconut oil and palm oil, are also an important component of fat intake. While LCT yields fatty acids which have chain length exceeding 12 carbons (usually C14-C22), MCT yields fatty acids which have carbon length lower than 12 (usually C6-C10). The diversity in fatty acid structure resulting from differences in chain length, degree of unsaturation, and position and stereoisomeric configuration of the double bonds may affect the metabolic fate of the fatty acid and the rate of fatty acid oxidation. The general trend in animal and human studies measuring fatty acid oxidation using isotope-labelled fatty acids (137) or indirect calorimetry can be summarized as follows:

1. Oxidation of saturated fatty acids decreases with increasing carbon (C) length (laurate C12 > myristate C14 > palmitate $\mathrm{C} 16$ > stearate C18), with medium-chain fatty acids (8-12 carbons) being oxidized the most rapidly.
2. Oxidation rates of long-chain unsaturated fatty acids (oleic, linoleic, linolenic) are more rapid than those for long-chain saturated fatty acids (palmitic, stearic).

3. Differences in oxidation rates between various subtypes unsaturated fatty acids (oleic vs. linoleic vs. linolenic) are less clear, whether between monounsaturated fatty acids (MUFAs) and polyunsaturated fatty acids (PUFAs) or between n3-PUFA and n6-PUFA.

There are indeed several acute studies in humans showing that the thermic effects of meals rich in MCT are greater than those rich in LCT or that diets high in PUFAs or MUFAs are more thermogenic than those high in saturated fatty acids $(6,138-141)$, with no differences between meals rich in PUFAs versus MUFAs in postprandial thermogenesis $(141,142)$. A dose-response study in a respiratory chamber investigating the thermogenic potential of MCT, when consumed as an integral part of the typical Western diet in non-obese men, has shown that $5-10 \mathrm{~g}$ of MCT ingested with each of the three meals (breakfast, lunch and dinner), in substitution of LCT, was well tolerated and caused a 5\% increase in 24-h EE (143), which resulted from increases in both fat and carbohydrate oxidation. Several mechanisms have been put forward to explain the thermogenic effects of MCT, and these centre upon its unique absorption and metabolic fate (through metabolic pathways which are energetically more costly), rapid entry in the mitochondrial oxidation pathway without requirement for carnitine and activation of the SNS (138). The findings that the elevation in 24-h EE with increasing dietary ratio of MCT : LCT (143) was associated with augmented urinary excretion rate of NA also suggest a specific role for enhanced SNS activity contributing to the thermogenic effects of MCT. The possibility that, on a cumulative basis, the increased EE with consumption of diets rich in MCT can have a significant impact on body weight and body composition is supported by the demonstrations that consumption of a diet rich in MCT for 4 weeks results in greater loss of adipose mass than with LCT (144). Furthermore, consumption of MCT oil (18-24 g) daily for 16 weeks as part of a weight-loss plan improves the losses in body weight and body fat (by about $1.5 \mathrm{~kg}$ ) without adverse metabolic profile compared with olive oil (145), thereby underscoring the suggestion that MCT can be considered as safe functional food ingredient. More recently, dietary supplementation with PUFA-(linoleic)-rich safflower oil $\left(8 \mathrm{~g} \mathrm{~d}^{-1}\right)$ for 36 weeks has also been reported to reduce trunk fat, increase lean mass and improve glucose profile in obese women with type 2 diabetes (146). Although supplementation with conjugated linolenic acid resulted in reduced adipose mass, there was no improvement in lean body mass nor in glucose profile (146). That diminished body fat with PUFA-enriched diets may result in part from enhanced thermogenesis and in part from nutri- 
ent partitioning in favour of lean body mass was recently documented in rats showing weight regain after caloric restriction (147). The results of these studies involving isocaloric refeeding on high-fat diets varying in fatty acid composition demonstrate that (i) independently of the $\mathrm{n} 6: \mathrm{n} 3$ ratio, linoleic acid and $\alpha$-linolenic acid reduce the efficiency of fat deposition, and that (ii) their main metabolites - arachidonic acid and docosahexaenoic acid (DHA), respectively - induce disproportionately greater reduction in the efficiency of fat regain. Taken together, the possibility therefore arises that diets enriched with PUFA as linoleic acid and/or $\alpha$-linolenic acid, or with their main metabolites, in particular DHA (147) or DHA derivatives (148), may have relevance as functional food ingredients for enhancing thermogenesis, improving body composition and insulin sensitivity in humans.

\section{Multiple targets and common targets}

From the overview above, one could conclude that in the present state-of-knowledge, the compounds categorized under methylxanthines, polyphenols, capsinoids and certain fatty acids (MCT and PUFA) confer the greatest potential as stimulators of thermogenesis and fat oxidation in obesity management. It is therefore not surprising that there is currently considerable impetus towards developing nutraceutical and functional food products that contain various combinations of these ingredients, particularly in the light of evidence that in addition to influencing resting EE and 24-h $\mathrm{EE}$, they may also contribute to negative fat balance through their effects in increasing spontaneous physical activity (e.g. caffeine), in reducing fat absorption (e.g. calcium, catechin polyphenols) or in promoting satiety (caffeine, capsaicins and MCT). Indeed, the view that targeting thermogenesis will almost inevitably lead to compensatory increase in food intake is not supported by the demonstrations over the past decades that, like the numerous $\beta_{3}$-adrenoceptor agonists that have been screened $(34,149)$, the administration of the bioactive food ingredients with thermogenic potentials discussed above either reduced energy intake or had no impact on food intake $(6,73,76,99,144)$.

\section{Molecular-physiological targets}

Keeping in mind that the mechanistic basis underlying the impact of such widely varying classes of compounds on thermogenesis and fat metabolism is likely to involve a multitude of targets in tissues/organs, it is nonetheless of interest to underscore the fact that, based on human and animal studies, they all seem to share two main 'global' peripheral targets. They not only exert their effects on the sympathoadrenal system and catecholamine actions (i.e. as sympathomimetics) thereby leading to enhance thermogenesis, but also are capable of stimulating fatty acid oxidation per se via the AMPK signalling pathway leading to ACC inhibition (i.e. ACC inhibitors). Indeed, there is evidence, from both in vitro and in vivo studies in rodents, that the AMPK-ACC pathway leading to enhanced flux of fatty acids in the mitochondrial $\beta$-oxidation can be modulated by caffeine or capsaicin-like compounds in skeletal muscle (150-152), by salicylates in the liver (153), by catechin polyphenols in liver, adipose tissue and skeletal muscle (154), by numerous other polyphenols that include resveratrol, catechins, curcumin, genistein, quercetin, kaempferol and isoflavones in several tissues (155-157) or by PUFA in liver and skeletal muscle (158). Furthermore, the fact that increasing the fatty acid availability increases AMPK activity independent of changes in the cellular energy charge supports the view that fatty acids may modulate AMPK allosterically (158). A mechanistic model integrating the mechanisms by which these bioactive ingredients - as sympathomimetics and ACC inhibitors - may be operating in coordination to enhance thermogenesis and fat oxidation is presented schematically in Fig. 4.

\section{Skeletal muscle and brown adipose tissue targets}

Which organs and tissues contribute most importantly to the thermogenic effects of these bioactive food ingredients is uncertain, amidst decades-old controversies about the importance of skeletal muscle as a major site of sympathomimetic-mediated thermogenesis (159-161) and about the amount and functionality of BAT in adult humans (162). The notion of targeting BAT for enhancing thermogenesis in human obesity management has recently been revitalized by investigations, using positron emission tomography coupled to computed tomography (PET/CT) scanning, which have revealed the presence of substantial amount of BAT in neck and shoulder region that become apparent by relatively short exposure to mild cold through increased SNS activity (162,163). A more recent study (164) has revealed the presence of UCP1 in supraclavicular adipose tissue even when the results of PET/CT scans are negative (most likely due to suboptimal sensitivity of standard PET/CT), thereby reinforcing the contention that the prevalence of BAT is higher than so far recognized in adult humans. As the thermogenic effects of xanthines, polyphenols, capsaicin-like compounds and PUFA have all been shown to be capable of stimulating the SNS-BAT axis in rodents $(18,63,76,93,165)$, the plausibility that these bioactive food ingredients, via their sympathomimetic properties, could be exerting part of their thermogenic effects through (re)activation of BAT in humans can no longer be disregarded. Indeed, based on data about the high rate of $\mathrm{O}_{2}$ consumption of this tissue in response to NA in hyperphagic rats exhibiting diet-induced thermogenesis $\left(1.7 \mathrm{~mL} \mathrm{O}_{2} \mathrm{~g}^{-1} \mathrm{~min}^{-1}\right)$, Rothwell and Stock (166) have argued that the activation of some $50 \mathrm{~g}$ of active BAT by 

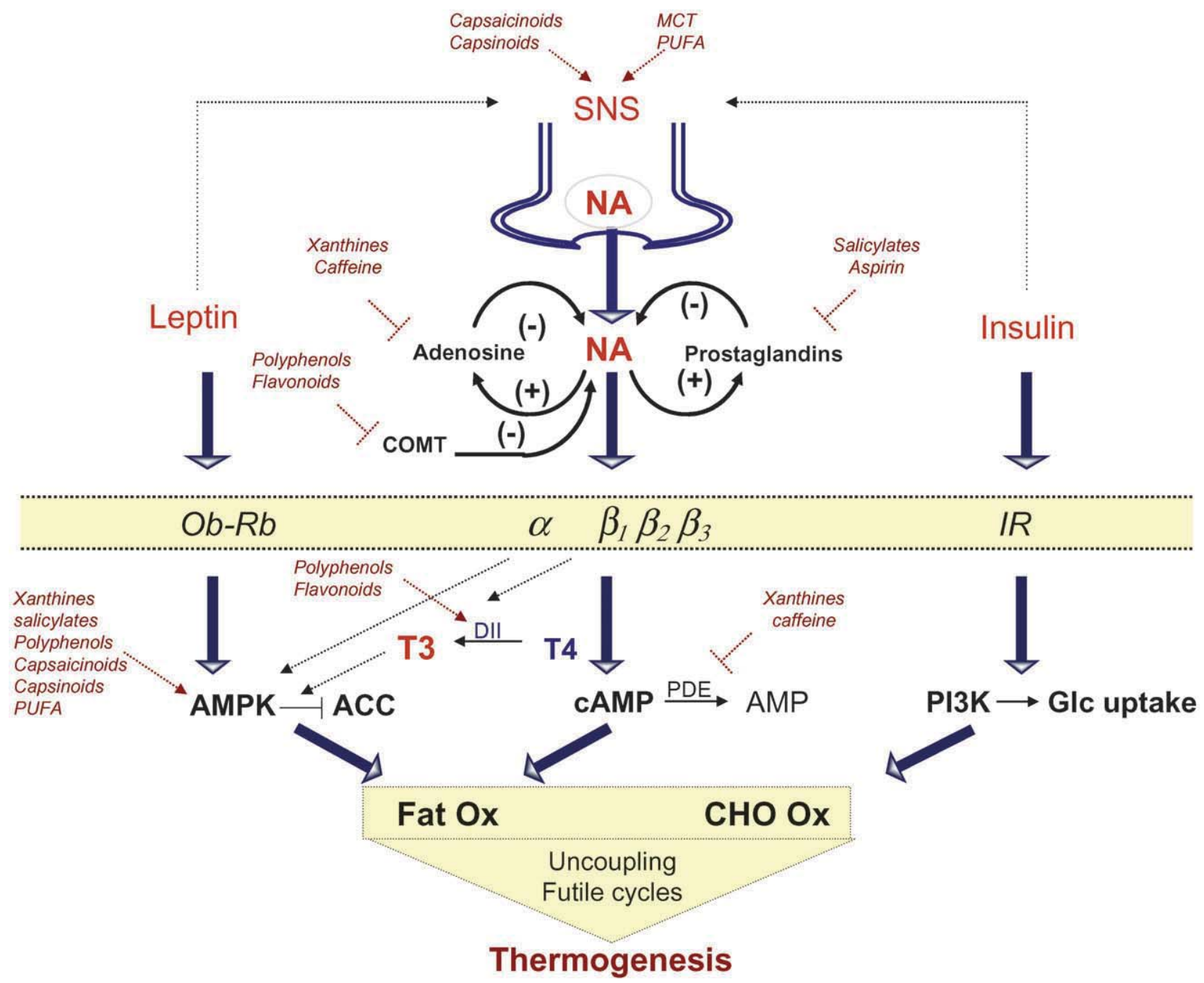

Figure 4 Main pathways in neuro-hormonal control of thermogenesis and fat oxidation, and possible molecular targets for bioactive food ingredients namely along the NA-CAMP pathway and along the AMPK-ACC2 pathway. From a physiological standpoint, leptin and insulin can act both centrally via SNS-NA-CAMP axis and peripherally via leptin receptors $(\mathrm{Ob}-\mathrm{Rb})$ and insulin receptors (IR), respectively, to influence thermogenesis fuelled by fat oxidation (Fat OX) and carbohydrate oxidation (CHO OX). Moreover, adrenoceptor stimulation of the deiodinase II enzyme (DII) can enhance peripheral conversion of the thyroid hormone T4 to its biologically more active form T3, which in turn can, like leptin, modulate the AMPK-ACC pathway that exerts control over fatty acid oxidation. Note that all the bioactive food ingredients depicted here have the dual property of modulating both the NA-CAMP pathway and AMPK-ACC pathway, i.e. they function as both sympathomimetics and ACC2 inhibitors in enhancing thermogenesis fuelled by fat oxidation. ACC, acetyl-CoA carboxylase; AMPK, AMP-activated protein kinase; NA, noradrenaline; SNS, sympathetic nervous system.

NA in an average 'sedentary' man spending 2,500 kcal d ${ }^{-1}$ would indeed correspond to an increase of about $20 \%$ in daily EE. Thus, although the role of BAT in the regulation of energy balance in humans has yet to be established, an apparently trivial amount of this tissue, if activated, could have a profound influence on energy balance, as $10-20 \%$ of daily EE (i.e. $250-500 \mathrm{kcal}$ ) can make the difference between maintaining body weight or gaining 10-20 kg in a year. Indeed, an increase in daily EE of $10-20 \%$ corresponds to the level of diet-induced thermogenesis demonstrated among the more obesity-resistant participants in long-term human overfeeding studies that involved mea- surements of total EE $(167,168)$. Whether these values represent the maximal increase in (non-shivering) thermogenic capacity in humans is at present unknown, but in animals the maximal thermogenic capacity can be markedly increased through stimulation of BAT growth induced by sympathetic and thyroid hormone activation of adipocyte differentiation/proliferation $(162,166)$. The search for pharmaceutical and nutraceutical products that may increase the amount and activity of this BAT is therefore an appealing strategy for the management of human obesity via stimulation of metabolic rate in a tissue whose primary function is to produce heat. 


\section{Cardiac responses to stimulation of thermogenesis}

A concern that is often raised about strategies to manage obesity by targeting thermogenesis is that it will result in an increased heart rate. Indeed, as EE increases, the work done by the heart must also increase to meet the body's greater demand for oxygen. During exercise, there is a fairly close relationship between heart rate and $\mathrm{EE}$ to the extent that the field technique for continuously measuring heart rate has been used to estimate EE in humans. However, the relationship between $\mathrm{EE}$ and heart rate is curvilinear, and at low levels of EE, heart rate does not increase as steeply for a given change in EE, probably because of changes in stroke volume. Consequently, an increase in heart rate in response to an extra demand in oxygen resulting from a $10-20 \%$ increase in daily EE is likely to be marginal. It is, however, probable that a substantial increase in heart rate driven by much greater increases in daily EE will not be considered as clinically acceptable.

\section{Concluding remarks}

The use of dietary supplements, botanical/herbal preparations, nutraceuticals and functional foods in the management of body weight has generally been perceived by the medical establishment as essentially anecdotal. This is largely because there is little, if any, robust scientific data to support claims of anti-obesity efficacy for the vast majority of such products that are being proposed to the consumers. Unlike prescription and over-the-counter medications, the 'natural' dietary adjuvants currently on the market are not prospectively reviewed for safety and efficacy by major regulatory agencies, which only intervene if a given dietary supplement product is shown to present 'a significant or unreasonable risk'. Consequently, most of these products have not been studied in long-term prospective placebo-controlled clinical trials and reported in peer-reviewed medical journals. Nonetheless, it is a reality that many of these products do in fact contain one or more pharmacologically active ingredient that is known to possess thermogenic and fat-oxidizing properties in acute studies, but the question is always whether they are effective and safe at the doses prescribed and over the long term. With research likely to generate many new candidate bioactive food ingredients, with the market likely to be overwhelmed with new products containing combinations of these ingredients and with claims of a more effective multi-targeted approach for weight control, the challenge for regulatory agencies is to decide as to what type of safety and efficacy standards these singletarget or multi-target products should be subjected before being 'approved' as supplements or functional foods for the purpose of managing human obesity. In the meantime, it is relevant to draw attention to the fact that among the caffeine-containing beverages, catechins-containing green tea, spices rich in capsaicinoids/capsinoids, and oils rich in MCT, PUFA or DHA, there is likely to be at least one (and generally two or more) of these dietary ingredients that form an integral part of the diet in most cultures of the world today. It makes one wonder about the extent to which they could already be helping many of us to put our excess fat into the fire.

\section{Conflict of Interest Statement}

No conflict of interest was declared.

\section{Acknowledgements}

This work is supported by the Swiss National Science Foundation (Grants no. 31-130481).

\section{References}

1. Dulloo AG, Jacquet J, Solinas G, Montani JP, Schutz Y. Body composition phenotypes in pathways to obesity and the metabolic syndrome. Int J Obes 2010; 34(Suppl. 2): S4-S17.

2. Ravussin E, Gautier JF. Metabolic predictors of weight gain. Int J Obes 1999; 23(Suppl. 1): 37-41.

3. Stock MJ. Gluttony and thermogenesis revisited. Int J Obes 1999; 23: 1105-1117.

4. Astrup A, Raben A, Buemann B, Toubro S. Fat metabolism in the predisposition to obesity. Ann N Y Acad Sci 1997; 827: 417430 .

5. Blundell JE, Cooling J. Routes to obesity: phenotypes, food choices and activity. Br J Nutr 2000; 83(Suppl. 1): S33-S38.

6. Dulloo AG. Strategies to counteract readjustments toward lower metabolic rates during obesity management. Nutrition 1993; 9: 366-372.

7. Major GC, Doucet E, Trayhurn P, Astrup A, Tremblay A. Clinical significance of adaptive thermogenesis. Int J Obes 2007; 31: 204-212.

8. Dulloo AG. Suppressed thermogenesis as a cause for resistance to slimming and obesity rebound: adaptation or illusion? Int J Obes 2007; 31: 201-203.

9. Rosenbaum M, Hirsch J, Gallagher DA, Leibel RL. Long-term persistence of adaptive thermogenesis in subjects who have maintained a reduced body weight. Am J Clin Nutr 2008; 88: 906-912. 10. Dulloo AG, Seydoux J, Jacquet J. Adaptive thermogenesis and uncoupling proteins: a reappraisal of their roles in fat metabolism and energy balance. Physiol Behav 2004; 83: 587-602.

11. Bray GA, Greenway FL. Current and potential drugs for treatment of obesity. Endocr Rev 1999; 20: 805-875.

12. Dulloo AG, Miller DS. Obesity: a disorder of the sympathetic nervous system. World Rev Nutr Diet 1987; 50: 1-56.

13. Higgins HL, Means JH. The effect of certain drugs on the respiratory and gaseous metabolism in normal human subjects. J Pharmacol Exp Ther 1915; 7: 1-9.

14. Chen KK, Schmidt CF. Ephedrine and related substances. Medecine 1930; 9: 117-130.

15. Landsberg L, Young JB. Sympathoadrenal activity and obesity: physiological rationale for the use of adrenergic thermogenic drugs. Int J Obes 1992; 17(Suppl. 1): S29-S34. 
16. Snitker S, Macdonald I, Ravussin E, Astrup A. The sympathetic nervous system and obesity: role in aetiology and treatment. Obes Rev 2000; 1: 5-15.

17. Schutz Y. The adjustment of energy expenditure and oxidation to energy intake: the role of carbohydrate and fat balance. Int J Obes Relat Metab Disord 1993; 17(Suppl. 3): S23-S27.

18. Dulloo AG, Seydoux J, Girardier L. Dietary and pharmacological effectiveness of thermogenic stimulation in obesity treatment. In: Oomura Y, Tarui S, Inoue S, Shimazu T (eds). Progress in Obesity Research 1990. John Libbey \& Company Ltd: London, 1990, pp. 135-144.

19. Acheson KJ, Zahorska-Markiewicz B, Pittet PH, Anantharaman K, Jéquier E. Caffeine and coffee: their influence on metabolic rate and substrate utilization in normal weight and obese individuals. Am J Clin Nutr 1980; 33: 989-997.

20. Jung RT, Shetty PS, James WP, Barrand MA, Callingham BA. Caffeine: its effect on catecholamines and metabolism in lean and obese humans. Clin Sci (Lond) 1981; 60: 527-535.

21. Dulloo AG, Geissler C, Horton T, Collins A, Miller DS. Normal caffeine consumption: influence on thermogenesis and daily energy expenditure in lean and post-obese human volunteers. Am J Clin Nutr 1989; 49: 44-50.

22. Morgan JB, York DA, Wasilewska A, Portman J. A study of the thermic responses to a meal and to a sympathomimetic drug (ephedrine) in relation to energy balance in man. Br J Nutr 1982; 47: 21-32.

23. Astrup A, Lundsgaard C, Madsen J, Christensen NJ. Enhanced thermogenic responsiveness during chronic ephedrine treatment in man. Am J Clin Nutr 1985; 42: 83-94.

24. Dulloo AG, Miller DS. The thermogenic properties of ephedrine/methylxanthine mixtures: human studies. Int $J$ Obes 1986; 10: 467-481.

25. Astrup A, Toubro S, Cannon S, Hein P, Madsen J. Thermogenic synergism between ephedrine and caffeine in healthy volunteers: a double-blind, placebo-controlled study. Metabolism 1991; 40: 323-329.

26. Dulloo AG, Miller DS. Ephedrine, caffeine and aspirin: 'overthe-counter' drugs that interact to stimulate thermogenesis in the obese. Nutrition 1989; 5: 7-9.

27. Horton TJ, Geissler CA. Aspirin potentiates the effect of ephedrine on the thermogenic response to a meal in obese but not lean women. Int J Obes 1991; 15: 359-366.

28. Dulloo AG. Ephedrine, xanthines and prostaglandininhibitors: actions and interactions in the stimulation of thermogenesis. Int J Obes 1993; 17(Suppl. 1): S35-S40.

29. Toubro S, Astrup AV, Breum L, Quaade F. Safety and efficacy of long-term treatment with ephedrine, caffeine and an ephedrine/ caffeine mixture. Int J Obes Relat Metab Disord 1993; 17(Suppl. 1): S69-S72.

30. Daly PA, Krieger DR, Dulloo AG, Young JB, Landsberg L. Ephedrine, caffeine and aspirin: safety and efficacy for treatment of human obesity. Int J Obes 1993; 17(Suppl. 1): S73-S78.

31. Molnár D, Török K, Erhardt E, Jeges S. Safety and efficacy of treatment with an ephedrine/caffeine mixture. The first doubleblind placebo-controlled pilot study in adolescents. Int J Obes 2000; 24: 1573-1578.

32. Greenway FL. The safety and efficacy of pharmaceutical and herbal caffeine and ephedrine use as a weight loss agent. Obes Rev 2001; 2: 199-211.

33. Arch JR, Ainsworth AT, Cawthorne MA, Piercy V, Sennitt MV, Thody VE et al. Atypical beta-adrenoceptor on brown adipocytes as target for anti-obesity drugs. Nature 1984; 309: 163-165.

34. Arch JR. The discovery of drugs for obesity, the metabolic effects of leptin and variable receptor pharmacology: perspectives from beta3-adrenoceptor agonists. Naunyn Schmiedebergs Arch Pharmacol 2008; 378: 225-240.

35. Minokoshi Y, Kim YB, Peroni OD, Fryer LG, Müller C, Carling D et al. Leptin stimulates fatty-acid oxidation by activating AMP-activated protein kinase. Nature 2002; 41: 339343.

36. Abu-Elheiga L, Matzuk MM, Abo-Hashema KA, Wakil SJ. Continuous fatty acid oxidation and reduced fat storage in mice lacking acetyl-CoA carboxylase 2. Science 2001; 291: 26132616.

37. Choi CS, Savage DB, Abu-Elheiga L, Liu ZX, Kim S, Kulkarni A et al. Continuous fat oxidation in acetyl-CoA carboxylase 2 knockout mice increases total energy expenditure, reduces fat mass, and improves insulin sensitivity. Proc Natl Acad Sci U S A 2007; 104: 16480-16485.

38. Clapham JC. Fat oxidation in obesity: druggable or risky enterprise. Idrugs 2004; 7: 238-242.

39. Corbett JW. Review of recent acetyl-CoA carboxylase inhibitor patents: mid-2007-2008. Expert Opin Ther Pat 2009; 19: 943-956.

40. Hoehn KL, Turner N, Swarbrick MM, Wilks D, Preston E, Phua Y et al. Acute or chronic upregulation of mitochondrial fatty acid oxidation has no net effect on whole-body energy expenditure or adiposity. Cell Metab 2010; 11: 70-76.

41. Harwood HJ Jr, Petras SF, Shelly LD, Zaccaro LM, Perry DA, Makowski MR et al. Isozyme-nonselective N-substituted bipiperidylcarboxamide acetyl-CoA carboxylase inhibitors reduce tissue malonyl-CoA concentrations, inhibit fatty acid synthesis, and increase fatty acid oxidation in cultured cells and in experimental animals. J Biol Chem 2003; 278: 37099-37111.

42. Savage DB, Choi CS, Samuel VT, Liu ZX, Zhang D, Wang A et al. Reversal of diet-induced hepatic steatosis and hepatic insulin resistance by antisense oligonucleotide inhibitors of acetyl-CoA carboxylases 1 and 2. J Clin Invest 2006; 116: 817-824.

43. Randle PJ, Garland P, Hales LN, Newsholme EA. The glucose fatty acid cycle, its role in insulin sensitivity and the metabolic disturbances of diabetes mellitus. Lancet 1963; 1: 785-789.

44. Kiens B, Alsted T, Jeppesen J. Exercise metabolism: regulation of fat metabolism and potential targets. Obes Rev 2011 (in press). 45. Haller CA, Benowitz NL. Adverse cardiovascular and central nervous system events associated with dietary supplements containing ephedra alkaloids. N Engl J Med 2000; 343: 1833-1838. 46. Boozer CN, Nasser JA, Heymsfield SB, Wang V, Chen G, Solomon JL. An herbal supplement containing Ma HuangGuarana for weight loss: a randomized, double-blind trial. Int J Obes 2001; 25: 316-324.

47. Boozer CN, Daly PA, Homel P, Solomon JL, Blanchard D, Nasser JA et al. Herbal Ephedra/Caffeine for weight loss: a 6-month randomized safety and efficacy trial. Int J Obes 2002; 26: 593-604.

48. Palamar J. How ephedrine escaped regulation in the United States: a historical review of misuse and associated policy. Health Policy 2011; 99: 1-9.

49. Gougeon R, Harrigan K, Tremblay JF, Hedrei P, Lamarche M, Morais JA. Increase in the thermic effect of food in women by adrenergic amines extracted from citrus aurantium. Obes Res 2005; 13: 1187-1194.

50. Preuss HG, DiFerdinando D, Bagchi M, Bagchi D. Citrus aurantium as a thermogenic, weight-reduction replacement for ephedra: an overview. J Med 2002; 33: 247-264.

51. Haaz S, Fontaine KR, Cutter G, Limdi N, Perumean-Chaney $\mathrm{S}$, Allison DB. Citrus aurantium and synephrine alkaloids in the treatment of overweight and obesity: an update. Obes Rev 2006; 7: 79-88. 
52. Preuss HG, Rao CV, Garis R, Bramble JD, Ohia SE, Bagchi $\mathrm{M}$ et al. An overview of the safety and efficacy of a novel, natural(-)-hydroxycitric acid extract (HCA-SX) for weight management. J Med 2004; 35: 33-48.

53. Sullivan AC, Hamilton JG, Miller ON, Wheatley VR. Inhibition of lipogenesis in rat liver by (-)-hydroxycitrate. Arch Biochem Biophys 1972; 150: 183-190.

54. Kriketos AD, Thompson HR, Greene H, Hill JO. (-)hydroxycitric acid does not affect energy expenditure and substrate oxidation in adult males in post-absorptive state. Int J Obes 1999; 23: 867-873.

55. Heymsfield SB, Allison DB, Vasseli JR, Pietrobelli A, Greenfield D, Nunez C. Garcinia cambogia (hydroxycitric acid) as a potential anti-obesity agent. JAMA 1998; 280: 1596-1600.

56. Acheson KJ, Gremaud G, Meirim I, Montigon F, Krebs Y, Fay LB et al. Metabolic effects of caffeine in humans: lipid oxidation or futile cycling? Am J Clin Nutr 2004; 79: 40-46.

57. Groop LC, Bonadonna RC, Shank M, Petrides AS, DeFronzo RA. Role of free fatty acids and insulin in determining free fatty acid and lipid oxidation in man. J Clin Invest 1991; 87: 8389.

58. Bracco D, Ferrarra JM, Arnaud MJ, Jéquier E, Schutz Y. Effects of caffeine on energy metabolism, heart rate, and methylxanthine metabolism in lean and obese women. Am J Physiol 1995; 269: E671-E678.

59. Dulloo AG, Duret C, Rohrer D, Girardier L, Mensi N, Fathi $\mathrm{M}$ et al. Efficacy of a green tea extract rich in catechin polyphenols and caffeine in increasing $24 \mathrm{~h}$ energy expenditure and fat oxidation in humans. Am J Clin Nutr 1999; 70: 1040-1045.

60. Borchardt RT, Huber JA. Catechol O-methyltransferase. 5. Structure-activity relationships for inhibition by flavonoids. J Med Chem 1975; 18: 120-122.

61. Gugler R, Dengler HJ. Inhibition of human liver catechol-Omethyltransferase by flavonoids. Naunyn Schmiedebergs Arch Pharmacol 1973; 276: 223-233.

62. Chen D, Wang CY, Lambert JD, Ai N, Welsh WJ, Yang CS. Inhibition of human liver catechol-O-methyltransferase by tea catechins and their metabolites: structure-activity relationship and molecular-modeling studies. Biochem Pharmacol 2005; 69: 15231531.

63. Dulloo AG, Seydoux J, Girardier L, Chantre P, Vandermander J. Green tea and thermogenesis: interaction between catechinpolyphenols, caffeine and sympathetic activity. Int J Obes 2000; 24: 252-258.

64. Rumpler W, Seale J, Clevidence B, Judd J, Wiley E, Yamamoto $\mathrm{S}$ et al. Oolong tea increases metabolic rate and fat oxidation in men. J Nutr 2001; 131: 2848-2852.

65. Bérubé-Parent S, Pelletier C, Doré J, Tremblay A. Effects of encapsulated green tea and Guarana extracts containing a mixture of epigallocatechin-3-gallate and caffeine on $24 \mathrm{~h}$ energy expenditure and fat oxidation in men. Br J Nutr 2005; 94: 432-436.

66. Rudelle S, Ferruzzi MG, Cristiani I, Moulin J, Macé K, Acheson KJ et al. Effect of a thermogenic beverage on 24-hour energy metabolism in humans. Obesity (Silver Spring) 2007; 15: 349-355.

67. Venables MC, Hulston CJ, Cox HR, Jeukendrup AE. Green tea extract ingestion, fat oxidation, and glucose tolerance in healthy humans. Am J Clin Nutr 2008; 87: 778-784.

68. Thielecke F, Rahn G, Böhnke J, Adams F, Birkenfeld AL, Jordan $\mathrm{J}$ et al. Epigallocatechin-3-gallate and postprandial fat oxidation in overweight/obese male volunteers: a pilot study. Eur J Clin Nutr 2010; 64: 704-713.

69. Lonac MC, Richards JC, Schweder MM, Johnson TK, Bell C. Influence of short-term consumption of the caffeine-free, epigallocatechin-3-gallate supplement, Teavigo, on resting metabolism and the thermic effect of feeding. Obesity (Silver Spring) 2011; 19: 298-304.

70. Ravussin E, Lillioja S, Anderson TE, Christin L, Bogardus C. Determinants of 24-hour energy expenditure in man. Methods and results using a respiratory chamber. J Clin Invest 1986; 78: 15681578.

71. Gregersen NT, Bitz C, Krog-Mikkelsen I, Hels O, Kovacs EM, Rycroft JA et al. Effect of moderate intakes of different tea catechins and caffeine on acute measures of energy metabolism under sedentary conditions. Br J Nutr 2009; 102: 1187-1194.

72. Hursel R, Viechtbauer W, Dulloo AG, Tremblay A, Tappy L, Rumpler W et al. The effects of catechin rich teas and caffeine on energy expenditure and fat oxidation: a meta-analysis. Obes Rev 2011; 12: e573-e581.

73. Hursel R, Viechtbauer W, Westerterp-Plantenga MS. The effects of green tea on weight loss and weight maintenance: a meta-analysis. Int J Obes 2009; 33: 956-961.

74. Phung OJ, Baker WL, Matthews LJ, Lanosa M, Thorne A, Coleman CI. Effect of green tea catechins with or without caffeine on anthropometric measures: a systematic review and metaanalysis. Am J Clin Nutr 2010; 91: 73-81.

75. Hursel R, Westerterp-Plantenga MS. Green tea catechin plus caffeine supplementation to a high-protein diet has no additional effect on body weight maintenance after weight loss. Am J Clin Nutr 2009; 89: 822-830.

76. Thavanesan N. The putative effects of green tea on body fat: an evaluation of the evidence and a review of the potential mechanisms. Br J Nutr 2011; doi: 10.1017/S00071145110038490011 77. Gruendel S, Garcia AL, Otto B, Mueller C, Steiniger J, Weickert MO et al. Carob pulp preparation rich in insoluble dietary fiber and polyphenols enhances lipid oxidation and lowers postprandial acylated ghrelin in humans. J Nutr 2006; 136: $1533-$ 1538 .

78. Baur JA, Pearson KJ, Price NL, Jamieson HA, Lerin C, Kalra A et al. Resveratrol improves health and survival of mice on a high-calorie diet. Nature 2006; 444: 337-342.

79. Nieman DC, Williams AS, Shanely RA, Jin F, McAnulty SR, Triplett NT et al. Quercetin's influence on exercise performance and muscle mitochondrial biogenesis. Med Sci Sports Exerc 2010; 42: $338-345$.

80. Davis JM, Carlstedt CJ, Chen S, Carmichael MD, Murphy EA. The dietary flavonoid quercetin increases $\operatorname{VO}(2 \max )$ and endurance capacity. Int J Sport Nutr Exerc Metab 2010; 20: 56-62.

81. Décordé K, Teissèdre PL, Sutra T, Ventura E, Cristol JP, Rouanet JM. Chardonnay grape seed procyanidin extract supplementation prevents high-fat diet-induced obesity in hamsters by improving adipokine imbalance and oxidative stress markers. Mol Nutr Food Res 2009; 53: 659-666.

82. Hollis JH, Houchins JA, Blumberg JB, Mattes RD. Effects of concord grape juice on appetite, diet, body weight, lipid profile, and antioxidant status of adults. J Am Coll Nutr 2009; 28: 574582.

83. Oi-Kano Y, Kawada T, Watanabe T, Koyama F, Watanabe K, Senbongi R et al. Oleuropein, a phenolic compound in extra virgin olive oil, increases uncoupling protein 1 content in brown adipose tissue and enhances noradrenaline and adrenaline secretions in rats. J Nutr Sci Vitaminol 2008; 54: 363-370.

84. Fukuchi Y, Hiramitsu M, Okada M, Hayashi S, Nabeno Y, Osawa $\mathrm{T}$ et al. Lemon polyphenols (hesperidin) suppress dietinduced obesity by up-regulation of mRNA levels of the enzymes involved in beta-oxidation in mouse white adipose tissue. J Clin Biochem Nutr 2008; 43: 201-209. 
85. Ejaz A, Wu D, Kwan P, Meydani M. Curcumin inhibits adipogenesis in 3T3-L1 adipocytes and angiogenesis and obesity in C57/BL mice. J Nutr 2009; 139: 919-925.

86. Cho AS, Jeon SM, Kim MJ, Yeo J, Seo KI, Choi MS et al. Chlorogenic acid exhibits anti-obesity property and improves lipid metabolism in high-fat diet-induced-obese mice. Food Chem Toxicol 2010; 48: 937-943.

87. Ørgaard A, Jensen L. The effects of soy isoflavones on obesity. Exp Biol Med (Maywood) 2008; 233: 1066-1080.

88. Cederroth CR, Vinciguerra M, Kühne F, Madani R, Doerge $\mathrm{DR}$, Visser TJ et al. A phytoestrogen-rich diet increases energy expenditure and decreases adiposity in mice. Environ Health Perspect 2007; 115: 1467-1473.

89. da-Silva WS, Harney JW, Kim BW, Li J, Bianco SD, Crescenzi A et al. The small polyphenolic molecule kaempferol increases (skeletal muscle myocyte) cellular energy expenditure and thyroid hormone activation. Diabetes 2007; 56: 767-776.

90. Hughes LA, Arts IC, Ambergen T, Brants HA, Dagnelie PC, Goldbohm RA et al. Higher dietary flavone, flavonol, and catechin intakes are associated with less of an increase in BMI over time in women: a longitudinal analysis from the Netherlands Cohort Study. Am J Clin Nutr 2008; 88: 1341-1352.

91. Henry CJK, Emery P. Effects of spiced food on metabolic rate. Hum Nutr Clin Nutr 1986; 40C: 165-168.

92. Yoshioka M, St-Pierre S, Suzuki M, Tremblay A. Effects of red pepper added to high-fat and high-carbohydrate meals on energy metabolism and substrate utilization in Japanese women. Br J Nutr 1998; 80: 503-510.

93. Westerterp-Plantenga M, Diepvens K, Joosen AM, BérubéParent S, Tremblay A. Metabolic effects of spices, teas, and caffeine. Physiol Behav 2006; 89: 85-91.

94. Yoshioka M, Doucet E, Drapeau V, Dionne I, Tremblay A. Combined effects of red pepper and caffeine consumption on $24 \mathrm{~h}$ energy balance in subjects given free access to foods. $\mathrm{Br} \mathrm{J} \mathrm{Nutr}$ 2001; 85: 203-211.

95. Ludy MJ, Mattes RD. The effects of hedonically acceptable red pepper doses on thermogenesis and appetite. Physiol Behav 2011; 102: 251-258.

96. Ohnuki K, Niwa S, Maeda S, Inoue N, Yazawa S, Fushiki T. $\mathrm{CH}-19$ sweet, a non-pungent cultivar of red pepper, increased body temperature and oxygen consumption in humans. Biosci Biotechnol Biochem 2001; 65: 2033-2036.

97. Josse AR, Sherriffs SS, Holwerda AM, Andrews R, Staples AW, Phillips SM. Effects of capsinoid ingestion on energy expenditure and lipid oxidation at rest and during exercise. Nutr Metab (Lond) 2010; 7: 65.

98. Galgani JE, Ravussin E. Effect of dihydrocapsiate on resting metabolic rate in humans. Am J Clin Nutr 2010; 92: 10891093.

99. Snitker S, Fujishima Y, Shen H, Ott S, Pi-Sunyer X, Furuhata $\mathrm{Y}$ et al. Effects of novel capsinoid treatment on fatness and energy metabolism in humans: possible pharmacogenetic implications. Am J Clin Nutr 2009; 89: 45-50.

100. Zemel MB. The role of dairy foods in weight management. $J$ Am Coll Nutr 2005; 24(Suppl.): 537S-546S.

101. Bortolotti M, Rudelle S, Schneiter P, Vidal H, Loizon E, Tappy L et al. Dairy calcium supplementation in overweight or obese persons: its effect on markers of fat metabolism. Am J Clin Nutr 2008; 88: 877-885.

102. Boon N, Hul GB, Stegen JH, Sluijsmans WE, Valle C, Langin $\mathrm{D}$ et al. An intervention study of the effects of calcium intake on faecal fat excretion, energy metabolism and adipose tissue mRNA expression of lipid-metabolism related proteins. Int J Obes 2007; 31: 1704-1712.
103. Chan She Ping-Delfos W, Soares M. Diet induced thermogenesis, fat oxidation and food intake following sequential meals: influence of calcium and vitamin D. Clin Nutr 2011; 30: 376-383 (Epub ahead of print).

104. Kaciuba-Uściłko H, Nazar K, Chwalbińska-Moneta J, Ziemba A, Kruk B, Szczepanik J et al. Effect of phosphate supplementation on metabolic and neuroendocrine responses to exercise and oral glucose load in obese women during weight reduction. $J$ Physiol Pharmacol 1993; 44: 425-440.

105. Jaedig S, Henningsen NC. Increased metabolic rate in obese women after ingestion of potassium, magnesium- and phosphateenriched orange juice or injection of ephedrine. Int J Obes 1991; 15: 429-436.

106. Jaedig S, Lindgärde F, Arborelius M. Increased postprandial energy expenditure in obese women after peroral $\mathrm{K}$ - and Mg-phosphate. Miner Electrolyte Metab 1994; 20: 147-152.

107. Wylie-Rosett J. Evaluation of protein in dietary management of diabetes mellitus. Diabetes Care 1988; 11: 143-148.

108. Velasquez MT, Bhathena SJ. Role of dietary soy protein in obesity. Int J Med Sci 2007; 4: 72-82.

109. Liaset B, Madsen L, Hao Q, Criales G, Mellgren G, Marschall HU et al. Fish protein hydrolysate elevates plasma bile acids and reduces visceral adipose tissue mass in rats. Biochim Biophys Acta 2009; 1791: 254-262.

110. Pilon G, Ruzzin J, Rioux LE, Lavigne C, White PJ, Frøyland $\mathrm{L}$ et al. Differential effects of various fish proteins in altering body weight, adiposity, inflammatory status, and insulin sensitivity in high-fat-fed rats. Metabolism 2011; 60: 1122-1130 (Epub ahead of print).

111. Pilvi TK, Harala S, Korpela R, Mervaala EM. Effects of high-calcium diets with different whey proteins on weight loss and weight regain in high-fat-fed C57BL/6J mice. Br J Nutr 2009; 102: 337-341.

112. Royle PJ, Mc Intosh GH, Clifton PM. Whey protein isolate and glycomacropeptide decrease weight gain and alter body composition in male Wistar rats. Br J Nutr 2008; 100: 88-93.

113. El Hafidi M, Pérez I, Zamora J, Soto V, Carvajal-Sandoval G, Baños G. Glycine intake decreases plasma free fatty acids, adipose cell size, and blood pressure in sucrose-fed rats. Am J Physiol 2004; 287: R1387-R1393.

114. Opara EC, Petro A, Tevrizian A, Feinglos MN, Surwit RS. L-glutamine supplementation of a high fat diet reduces body weight and attenuates hyperglycemia and hyperinsulinemia in C57BL/6J mice. J Nutr 1996; 126: 273-279.

115. Layman DK, Walker DA. Potential importance of leucine in treatment of obesity and the metabolic syndrome. J Nutr 2006; 136(Suppl. 1): 319S-323S.

116. McKnight JR, Satterfield MC, Jobgen WS, Smith SB, Spencer $\mathrm{TE}$, Meininger $\mathrm{CJ}$ et al. Beneficial effects of $\mathrm{L}$-arginine on reducing obesity: potential mechanisms and important implications for human health. Amino Acids 2010; 39: 349-357.

117. Van Vught AJ, Heitmann BL, Nieuwenhuizen AG, Veldhorst MA, Brummer RJ, Westerterp-Plantenga MS. Association between dietary protein and change in body composition among children (EYHS). Clin Nutr 2009; 28: 684-688.

118. Van Vught AJ, Heitmann BL, Nieuwenhuizen AG, Veldhorst MA, Andersen LB, Hasselstrom $\mathrm{H}$ et al. Association between intake of dietary protein and 3-year-change in body growth among normal and overweight 6-year-old boys and girls (CoSCIS). Public Health Nutr 2010; 13: 647-653.

119. Mikkelsen PB, Toubro S, Astrup A. Effect of fat-reduced diets on 24-h energy expenditure: comparisons between animal protein, vegetable protein, and carbohydrate. Am J Clin Nutr 2000; 72: 1135-1141. 
120. Acheson KJ, Blondel-Lubrano A, Oguey-Araymon S, Beaumont M, Emady-Azar S, Ammon-Zufferey C et al. Protein choices targeting thermogenesis and metabolism. Am J Clin Nutr 2011; 93: 525-534.

121. Alfenas Rde C, Bressan J, Paiva AC. Effects of protein quality on appetite and energy metabolism in normal weight subjects. Arq Bras Endocrinol Metabol 2010; 54: 45-51.

122. Wu G. Amino acids: metabolism, functions, and nutrition. Amino Acids 2009; 37: 1-17.

123. Sharief NN, Macdonald I. Differences in dietary-induced thermogenesis with various carbohydrates in normal and overweight men. Am J Clin Nutr 1982; 35: 267-272.

124. Macdonald I. Differences in dietary-induced thermogenesis following the ingestion of various carbohydrates. Ann Nutr Metab 1984; 28: 226-230.

125. Tappy L, Jéquier E. Fructose and dietary thermogenesis. Am J Clin Nutr 1993; 58(Suppl.): 766S-770S.

126. Blaak EE, Saris WH. Postprandial thermogenesis and substrate utilization after ingestion of different dietary carbohydrates. Metabolism 1996; 45: 1235-1242.

127. Bray GA. Fructose: pure, white, and deadly? Fructose, by any other name, is a health hazard. J Diabetes Sci Technol 2010; 4: 1003-1007.

128. Stanhope KL, Schwarz JM, Keim NL, Griffen SC, Bremer $\mathrm{AA}$, Graham JL et al. Consuming fructose-sweetened, not glucosesweetened, beverages increases visceral adiposity and lipids and decreases insulin sensitivity in overweight/obese humans. J Clin Invest 2009; 119: 1322-1334.

129. Dulloo AG, Eisa OA, Miller DS, Yudkin J. A comparative study of the effects of white sugar, unrefined sugar and starch on the efficiency of food utilization and thermogenesis. Am J Clin Nutr 1985; 42: 214-219.

130. Dulloo AG, Girardier L. Influence of dietary composition on energy expenditure during recovery of body weight in the rat: implications for catch-up growth and obesity relapse. Metabolism 1992; 41: 1336-1342.

131. Walgren MC, Young JB, Kaufman LN, Landsberg L. The effects of various carbohydrates on sympathetic activity in heart and interscapular brown adipose tissue of the rat. Metabolism 1987; 36: 585-594.

132. Young JB, Weiss J, Boufath N. Effects of dietary monosaccharides on sympathetic nervous system activity in adipose tissues of male rats. Diabetes 2004; 53: 1271-1278.

133. Goseki-Sone M, Maruyama R, Sogabe N, Hosoi T. Effects of dietary lactose on long-term high-fat-diet-induced obesity in rats. Obesity (Silver Spring) 2007; 15: 2605-2613.

134. Mohammad MA, Sunehag AL, Rodriguez LA, Haymond MW. Galactose promotes fat mobilization in obese lactating and nonlactating women. Am J Clin Nutr 2011; 93: 374-381.

135. Ryttig KR, Lammert O, Nielsen E, Garby L, Poulsen K. The effect of a soluble dietary fibre supplement on 24-hour energy expenditure during a standardized physical activity programme. Int J Obes 1990; 14: 451-455.

136. Poppitt SD, Livesey G, Elia M. Energy expenditure and net substrate utilization in men ingesting usual and high amounts of nonstarch polysaccharide. Am J Clin Nutr 1998; 68: 820-826.

137. DeLany JP, Windhauser MM, Champagne CM, Bray GA. Differential oxidation of individual dietary fatty acids in humans. Am J Clin Nutr 2000; 72: 905-911.

138. St-Onge MP, Jones PJ. Physiological effects of medium-chain triglycerides: potential agents in the prevention of obesity. J Nutr 2002; 132: 329-332.

139. Piers LS, Walker KZ, Stoney RM, Soares MJ, O’Dea K. The influence of the type of dietary fat on postprandial fat oxidation rates: monounsaturated (olive oil) vs saturated fat (cream). Int $J$ Obes 2002; 26: 814-821.

140. Jones PJ, Jew S, AbuMweis S. The effect of dietary oleic, linoleic, and linolenic acids on fat oxidation and energy expenditure in healthy men. Metabolism 2008; 57: 1198-1203.

141. Casas-Agustench P, López-Uriarte P, Bulló M, Ros E, Gómez-Flores A, Salas-Salvadó J. Acute effects of three high-fat meals with different fat saturations on energy expenditure, substrate oxidation and satiety. Clin Nutr 2009; 28: 39-45.

142. Flint A, Helt B, Raben A, Toubro S, Astrup A. Effects of different dietary fat types on postprandial appetite and energy expenditure. Obes Res 2003; 11: 1449-1455.

143. Dulloo AG, Fathi M, Mensi N, Girardier L. Twenty-four hour energy expenditure and urinary catecholamines of humans consuming low-to-moderate amounts of medium-chain-triglycerides: a dose-response study in a respiratory chamber. Eur J Clin Nutr 1996; 50: 152-158.

144. St-Onge MP, Ross R, Parsons WD, Jones PJ. Medium-chain triglycerides increase energy expenditure and decrease adiposity in overweight men. Obes Res 2003; 11: 395-402.

145. St-Onge MP, Bosarge A, Goree LL, Darnell B. Medium chain triglyceride oil consumption as part of a weight loss diet does not lead to an adverse metabolic profile when compared to olive oil. Am Coll Nutr 2008; 27: 547-552.

146. Norris LE, Collene AL, Asp ML, Hsu JC, Liu LF, Richardson JR et al. Comparison of dietary conjugated linoleic acid with safflower oil on body composition in obese postmenopausal women with type 2 diabetes mellitus. Am J Clin Nutr 2009; 90: 468476.

147. Yepuri G, Marcelino H, Shahkhalili Y, Aprikian O, Macé K, Seydoux J et al. Dietary modulation of body composition and insulin sensitivity during catch-up growth in rats: effects of oils rich in n-6 or n-3 PUFA. Br J Nutr 2011; 105: 1750-1763.

148. Rossmeisl M, Jelenik T, Jilkova Z, Slamova K, Kus V, Hensler $\mathrm{M}$ et al. Prevention and reversal of obesity and glucose intolerance in mice by DHA derivatives. Obesity (Silver Spring) 2009; 17: 1023-1031.

149. Yamashita J, Onai T, York DA, Bray GA. Relationship between food intake and metabolic rate in rats treated with betaadrenoceptor agonists. Int J Obes 1994; 18: 429-433.

150. Egawa T, Hamada T, Ma X, Karaike K, Kameda N, Masuda $\mathrm{S}$ et al. Caffeine activates preferentially $\alpha 1$-isoform of 5 'AMPactivated protein kinase in rat skeletal muscle. Acta Physiol (Oxf) 2011; 201: 227-238.

151. Kim DH, Joo JI, Choi JW, Yun JW. Differential expression of skeletal muscle proteins in high-fat diet-fed rats in response to capsaicin feeding. Proteomics 2010; 10: 2870-2881.

152. Hwang SL, Yang BK, Lee JY, Kim JH, Kim BD, Suh KH et al. Isodihydrocapsiate stimulates plasma glucose uptake by activation of AMP-activated protein kinase. Biochem Biophys Res Commun 2008; 371: 289-293.

153. Dular U, Dakshinamurti K. Effect of salicylates on acetyl coenzyme A carboxylase. Biochem Pharmacol 1979; 28: 715718.

154. Murase T, Misawa K, Haramizu S, Hase T. Catechininduced activation of the LKB1/AMP-activated protein kinase pathway. Biochem Pharmacol 2009; 78: 78-84.

155. Um JH, Park SJ, Kang H, Yang S, Foretz M, McBurney MW et al. AMP-activated protein kinase-deficient mice are resistant to the metabolic effects of resveratrol. Diabetes 2010; 59: 554563.

156. Zheng J, Ramirez VD. Inhibition of mitochondrial proton F0F1-ATPase/ATP synthase by polyphenolic phytochemicals. $\mathrm{Br} J$ Pharmacol 2000; 130: 1115-1123. 
157. Cederroth CR, Vinciguerra M, Gjinovci A, Kühne F, Klein $\mathrm{M}$, Cederroth $\mathrm{M}$ et al. Dietary phytoestrogens activate AMPactivated protein kinase with improvement in lipid and glucose metabolism. Diabetes 2008; 57: 1176-1185.

158. Watt MJ, Steinberg GR, Chen ZP, Kemp BE, Febbraio MA. Fatty acids stimulate AMP-activated protein kinase and enhance fatty acid oxidation in L6 myotubes. J Physiol 2006; 574: 139147.

159. Astrup A, Bülow J, Madsen J, Christensen NJ. Contribution of BAT and skeletal muscle to thermogenesis induced by ephedrine in man. Am J Physiol 1985; 248: E507-E515.

160. Kurpad AV, Khan K, Calder AG, Elia M. Muscle and whole body metabolism after norepinephrine. Am J Physiol 1994; 266: E877-E884.

161. Dulloo AG. A sympathetic defense against obesity. Science 2002; 297: 780-781.

162. Nedergaard J, Cannon B. The changed metabolic world with human brown adipose tissue: therapeutic visions. Cell Metab 2010; 11: 268-272.
163. Richard D, Carpentier AC, Doré G, Ouellet V, Picard F. Determinants of brown adipocyte development and thermogenesis. Int J Obes 2010; 34(Suppl. 2): S59-S66.

164. Lee P, Zhao JT, Swarbrick MM, Gracie G, Bova R, Greenfield JR et al. High prevalence of brown adipose tissue in adult humans. J Clin Endocrinol Metab 2011; doi: 1210/jc.20110487 (Epub ahead of print).

165. Li JJ, Huang CJ, Xie D. Anti-obesity effects of conjugated linoleic acid, docosahexaenoic acid, and eicosapentaenoic acid. Mol Nutr Food Res 2008; 52: 631-645.

166. Rothwell NJ, Stock MJ. Diet-induced thermogenesis. In: Girardier L, Stock MJ (eds). Mammalian Thermogenesis. Chapman and Hall Ltd: London, UK, 1983, pp. 208-233. 167. Leibel RL, Rosenbaum M, Hirsch J. Changes in energy expenditure resulting from altered body weight. $N$ Engl J Med 1995; 332: 621-628.

168. Levine JA, Eberhardt NL, Jensen MD. Role of nonexercise activity thermogenesis in resistance to fat gain in humans. Science 1999; 283: 212-214. 